\title{
Spray drying of soymilk: evaluation of process yield and product quality
}

Olmos, B.D.F. ${ }^{\text {a }}$ Penha, C.B. ${ }^{\text {a }}$ Kurozawa, L.E. ${ }^{a^{*}}$

a School of Food Engineering. University of Campinas, Campinas, Brazil.

*E-mail of the corresponding author: louisek@unicamp.br

\begin{abstract}
The aim of this work was to evaluate the effect of inlet air temperature and gum Arabic concentration on yield of spray drying of soymilk and powder quality (moisture content, water activity and antioxidant capacity). Since soymilk had a significant lipid content, gum Arabic played a significant role as an emulsion stabilizer, improving process yield and preserving antioxidant capacity. However, temperature did not affect antioxidant capacity. The optimal condition to obtain higher antioxidant capacity was: $30 \%$ of gum Arabic and $160^{\circ} \mathrm{C}$. The powder obtained under optimized condition was characterized regarding to bulk density, particle size distribution and morphology.
\end{abstract}

Keywords: soymilk; spray drying; ferric reduction power FRAP; DPPH scavenging ability; scanning electron microscopy. 


\section{Introduction}

Recently, the ready-to-drink soymilk has become popular, in which sales volume of worldwide in 2015 reached 13.5 billion liters ${ }^{[1]}$. Vegan and helthy diet folowers are one of the major consumers because it is lactose- and gluten-free beverage and contains highquality proteins, dietary fiber and antioxidant compounds, such as phenolic compounds ${ }^{[2,3]}$. However, some conservation method is necessary in order to increase its shelf life. Of the several drying methods, spray drying is suitable for heat-sensitive products, such as soymilk, promoting higher retention of nutrients due to the short residence time ${ }^{[4]}$.

When exposed at higher temperature during spray drying, fat present in soymilk (18 g/100 g solids ${ }^{[5]}$ becomes molten, resulting in particle adhesion on the dryer chamber and low product recovery ${ }^{[6]}$. Part of this problem can be solved by adding a carrier agent to the feed solution before drying, in order to decrease the fat content ${ }^{[7]}$. Moreover, since soymilk is an oil-in-water emulsion, the thermodynamic instability of this system can result in larger oil droplets due to coalescence of droplets dispersed in soymilk. The larger the oil droplets are, the higher the breakup during atomization of the emulsion in the spray dryer chamber ${ }^{[8]}$. This breakup of the emulsion favors the increase in of the surface oil, decreasing the product recovery ${ }^{[9]}$. Thus, the addition of carrier agent with good emulsifying properties, such as gum Arabic, enhances emulsion stability and, as consequence, product recovery.

The objective of this work was to evaluate the effect of inlet air temperature and gum Arabic concentration on the process yield and powder quality (moisture content, water activity and antioxidant capacity).

\section{Materials and Methods}

\subsection{Material}

Soybean (Glycine max (L.) Merr.) cultivar BRS 257, which is lipoxygenase-free, was acquired from SL Alimentos (Mauá da Serra, Brazil). Gum Arabic (GA) Instantgum BB (Nexira, São Paulo, Brazil) was used as the wall material. DPPH 2,2-diphenyl-1picrylhydrazyl and TPTZ 2,4,6-tris(2-pyridyl)-S-triazine were used as reagent for the analysis of antioxidant capacity, and Trolox 6-hydroxy-2,5,7,8-tetramethylchroman-2carboxylic acid as standard (Sigma-Aldrich, Saint Louis, USA).

\subsection{Preparation of soymilk}

Soymilk was obtained according to Baú and $\mathrm{Ida}^{[2]}$. About $3 \mathrm{~kg}$ of soybeans were soaked in water at $1: 3$ ratio (w:w, soybean:water) for $12 \mathrm{~h}$ at $8^{\circ} \mathrm{C}$. The grains were drained and homogenized with distilled water at 1:8 ratio (w:w, soybean:water) using an industrial blender. The slurry was filtered and pasteurized at $90^{\circ} \mathrm{C}$ for $3 \mathrm{~min}$, obtaining the soymilk. The chemical composition of soymilk, obtained by $\mathrm{AOAC}^{[10]}$, was (wet basis): moisture 
content of $94.8 \pm 0.1 \%$, ash content of $0.2 \pm 0.0 \%$, lipid content of $1.3 \pm 0.1 \%$, protein content of $2.4 \pm 0.0 \%$ and carbohydrate content, calculated by difference, of $1.4 \%$. Samples were stored at $-18^{\circ} \mathrm{C}$ and thawed according to the quantity required for spray drying.

\subsection{Spray drying of soymilk}

Before spray drying, gum Arabic was dissolved in soymilk at different concentrations (Table 1) using a magnetic stirrer. After, the mixture were homogenized at 20,000 rpm for $5 \mathrm{~min}$ in order to emulsify the fat soymilk and break up the clots, returning to a fluid consistency. About $400 \mathrm{~g}$ of feed solution were fed into the laboratory scale spray dryer (MSD 1.0, Labmaq, Ribeirão Preto, Brazil) by a peristaltic bomb at flow rate of $0.4 \mathrm{~L} / \mathrm{h}$. The feed solution was atomized into spray dryer chamber by a two-fluid atomizer spray nozzle with an orifice of $0.7 \mathrm{~mm}$ in diameter, using compressed air at flow rate of $40 \mathrm{~L} / \mathrm{h}$. Inlet air temperature was used according to Table 1. For each assay, the collected powder was weighed for subsequent calculation of process yield, which was the ratio of total solids mass in the powder to total solids mass in the feed solution.

Spray drying experiments were carried out according to a central composite rotatable design (Table 1) in order to evaluate the effect of inlet air temperature and gum Arabic concentration on the responses process yield, moisture content, water activity and antioxidant capacity. Experimental data were fitted to Equation (1) ${ }^{[11]}$.

$$
y=b_{0}+b_{1} x_{1}+b_{2} x_{2}+b_{11} x_{1}^{2}+b_{22} x_{2}^{2}+b_{12} x_{2} x_{2}
$$

Where: $y$ is the response, $b_{0}, b_{1}$ and $b_{2}, b_{11}$ and $b_{22}$, and $b_{12}$ are the constant, linear, quadratic and cross-product regression coefficients, respectively, and $\mathrm{x}_{1}$ and $\mathrm{x}_{2}$ represent the coded values of the $T_{\text {in }}$ and GA variables, respectively.

Regression coefficients of the predictive models were obtained by the Protimiza software (http://experimental-design.protimiza.com.br). Coefficients within a confidence level above $90 \%$ were considered significant $(\mathrm{p}<0.1)$. Non-significant terms were eliminated, and the model was tested for adequacy by analysis of variance (Anova), coefficient of determination $\left(\mathrm{R}^{2}\right)$ and F-test. For powder moisture content, the analysis of results indicated the model was linear, and the expansion of the screening design to a central composite rotatable design, with the addition of axial points (tests 5 to 8), was not necessary. 
Table 1. Screening design for spray drying of soymilk, regression coefficients and Anova

\begin{tabular}{|c|c|c|c|c|c|c|c|}
\hline \multirow[t]{2}{*}{ Assay } & \multicolumn{2}{|c|}{$\begin{array}{c}\text { Independent } \\
\text { variables }\end{array}$} & \multicolumn{5}{|c|}{ Dependent variables } \\
\hline & $T_{\text {in }}$ & GA & $\mathbf{Y}$ & $\mathbf{X}$ & Aw & FRAP & DPPH \\
\hline 1 & 140 & 13 & 45.6 & $2.6 \pm 0.1$ & $0.149 \pm 0.006$ & $25.1 \pm 2.0$ & $243.3 \pm 14.8$ \\
\hline 2 & 180 & 13 & 54.1 & $1.1 \pm 0.0$ & $0.093 \pm 0.010$ & $30.2 \pm 0.3$ & $223.6 \pm 13.5$ \\
\hline 3 & 140 & 27 & 59.2 & $3.5 \pm 0.4$ & $0.043 \pm 0.002$ & $44.9 \pm 3.9$ & $514.3 \pm 15.7$ \\
\hline 4 & 180 & 27 & 60.5 & $1.4 \pm 0.4$ & $0.088 \pm 0.005$ & $46.6 \pm 0.8$ & $482.4 \pm 5.2$ \\
\hline 5 & 132 & 20 & 64.9 & - & $0.112 \pm 0.009$ & $40.3 \pm 2.3$ & $330.3 \pm 39.5$ \\
\hline 6 & 188 & 20 & 57.0 & - & $0.170 \pm 0.004$ & $36.6 \pm 0.5$ & $285.3 \pm 24.5$ \\
\hline 7 & 160 & 10 & 40.1 & - & $0.165 \pm 0.012$ & $26.6 \pm 0.7$ & $168.3 \pm 10.4$ \\
\hline 8 & 160 & 30 & 60.7 & - & $0.095 \pm 0.008$ & $43.7 \pm 1.1$ & $543.3 \pm 26.5$ \\
\hline 9 & 160 & 20 & 69.8 & $2.2 \pm 0.1$ & $0.168 \pm 0.012$ & $43.7 \pm 1.1$ & $343.6 \pm 3.5$ \\
\hline 10 & 160 & 20 & 64.2 & $2.0 \pm 0.2$ & $0.108 \pm 0.016$ & $37.0 \pm 0.6$ & $293.2 \pm 31.3$ \\
\hline 11 & 160 & 20 & 66.6 & $2.4 \pm 0.0$ & $0.122 \pm 0.006$ & $37.4 \pm 0.8$ & $319.3 \pm 8.7$ \\
\hline \multicolumn{8}{|c|}{ Regression coefficients } \\
\hline \multicolumn{3}{|c|}{$\mathrm{b}_{0}$} & 66.9 & 2.2 & 0.12 & 36.9 & 327.6 \\
\hline \multicolumn{3}{|c|}{$\mathrm{b}_{1}$} & NS & -0.9 & NS & NS & -14.4 \\
\hline \multicolumn{3}{|c|}{$b_{11}$} & -3.2 & - & NS & NS & NS \\
\hline \multicolumn{3}{|c|}{$\mathrm{b}_{2}$} & 6.1 & 0.3 & -0.03 & 7.6 & 132.52 \\
\hline \multicolumn{3}{|c|}{$b_{22}$} & -8.4 & - & NS & NS & 22.18 \\
\hline \multicolumn{3}{|c|}{$b_{12}$} & NS & NS & NS & NS & NS \\
\hline \multicolumn{3}{|c|}{$\mathrm{R}^{2}$} & 0.88 & 0.95 & 0.36 & 0.90 & 0.98 \\
\hline \multicolumn{3}{|c|}{$\mathrm{Fc}$} & 17.2 & 38.0 & 5.0 & 80.3 & 124.3 \\
\hline \multicolumn{3}{|c|}{$\mathrm{Ft}$} & 3.07 & 4.32 & 3.36 & 3.36 & 3.07 \\
\hline
\end{tabular}

NS is non-significant $(\mathrm{p}>0.1)$

\subsection{Analytical methods}

\subsubsection{Physicochemical properties of the powders}

Moisture content was determined gravimetrically in triplicate in an oven at $105^{\circ} \mathrm{C}$ for $24 \mathrm{~h}^{[10]}$. A thermohygrometer Aqualab (4 TEV, Decagon, Pullman, USA) was used to measure water activity at $25^{\circ} \mathrm{C}$. Bulk density was calculated by dividing the mass of powder by the volume occupied in the cylinder after tapped by hand. Particle size distribution and mean diameter particle $\mathrm{D}_{43}$ were obtained, in triplicate, using a laser light scattering analyzer (Mastersizer, model 2000, Malvern, UK). Particle microstructures were evaluated by a scanning electron microscope (Leo 440i, LEO Electron Microscopy/Oxford, Cambridge, England). 


\subsubsection{Antioxidant capacity of the powders}

Prior to the analysis, $0.5 \mathrm{~g}$ of powder were dissolved in $8 \mathrm{~mL}$ of destilled water. Antioxidant capacity by donating hydrogen atoms to the DPPH radical and by ferric reduction power FRAP were determined according to Brand-Williams et al. ${ }^{[12]}$ and Benzie and Strain ${ }^{[13]}$, respectively. For DPPH and FRAP method, after reaction, the sample absorbance was measured at 517 and $595 \mathrm{~nm}$, respectively, using an UV-visible spectrophotometer. Analytical curves with different concentrations of Trolox, ranging from 1,000 to $5,000 \mu \mathrm{M}$ for DPPH and 50 to $600 \mu \mathrm{M}$ for FRAP method, were used for the subsequent calculation of the results in $\mu \mathrm{mol}$ Trolox equivalent (TE)/g of soymilk solids. All assays were performed in triplicate.

\section{Results and discussion}

\subsection{Spray drying of soymilk}

The regression coefficients for the responses, F-values, $p$-values and $\mathrm{R}^{2}$ are presented in Table 1. After exclusion of non-significant terms $(p>0.1)$, the predictive models were tested for accuracy of fit by Anova. When the calculated F-value Fc was greater than the tabulated $\mathrm{F}$-value $\mathrm{Ft}$, the variation was explained by the regression and not by the residues. Thus the regression was significant, and the model could be considered predictive. Figure 1 shows the response surfaces generated by the proposed models.

Analyzing Figure 1(a), GA had greater influence on process yield than $T_{i n}$. As expected, the increase of GA up to $22.5 \%$ enhanced powder recovery, since the addition of carrier agent decreased the fat content in the feed solution. This fact reduces the particle adhesion on the dryer chamber, which could occur due to the fat melting during spray drying ${ }^{[7]}$. However, an opposite behavior could be seen at GA above $22.5 \%$. This result can be related to the high powder moisture content (Fig. 1(b)). Higher carrier agent concentration increases the feed viscosity, resulting in greater droplets atomized during spray drying. Thus, there is a poor heat and mass transfer between the droplets and drying air, resulting in the formation of wetter and sticker particles.

The antioxidant capacity of spray-dried soymilk ranged from 168.3 to $543.3 \mu \mathrm{mol} \mathrm{TE} / \mathrm{g}$ for DPPH and 25.1 to $46.6 \mu \mathrm{mol} \mathrm{TE} / \mathrm{g}$ solids of soymilk for FRAP method. Since soymilk solution presented $742.6 \pm 36.2$ and $200.2 \pm 6.2 \mu \mathrm{mol} \mathrm{TE} / \mathrm{g}$ solids, there was a retention of antioxidant capacity varying from 22.7 to $73.2 \%$ and 12.5 to $23.3 \%$, for DPPH and FRAP methods, respectively. Figures 1(c) and 1(d) show the positive effect of gum Arabic concentration on antioxidant capacity for both methods. Since soymilk had a significant lipid content, gum Arabic played a significant role in spray drying as an emulsion stabilizer, encapsulating and preserving the antioxidant substances present in soymilk. 


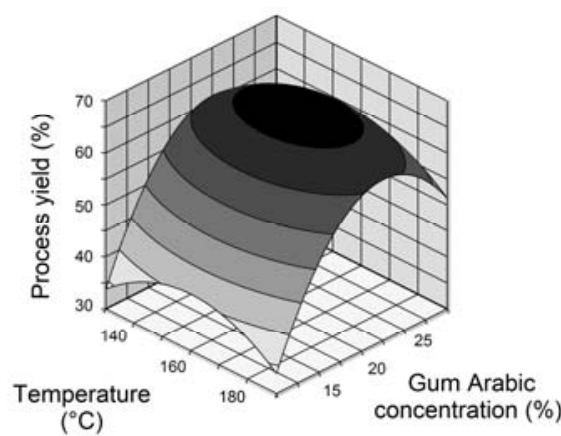

(a)

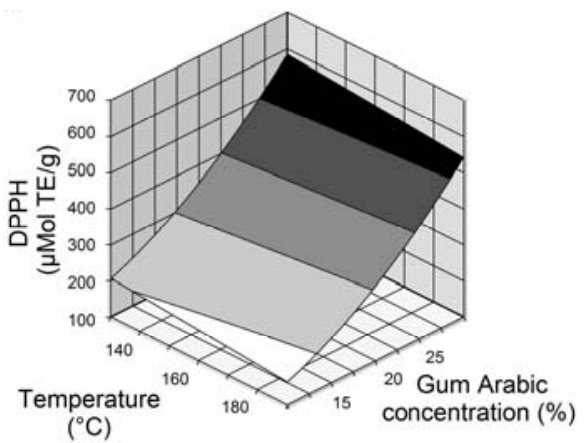

(c)

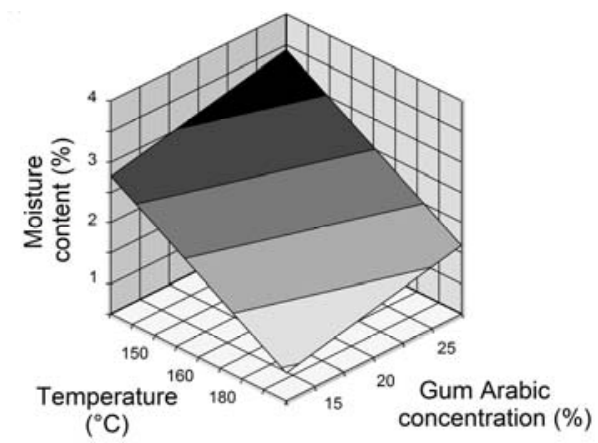

(b)

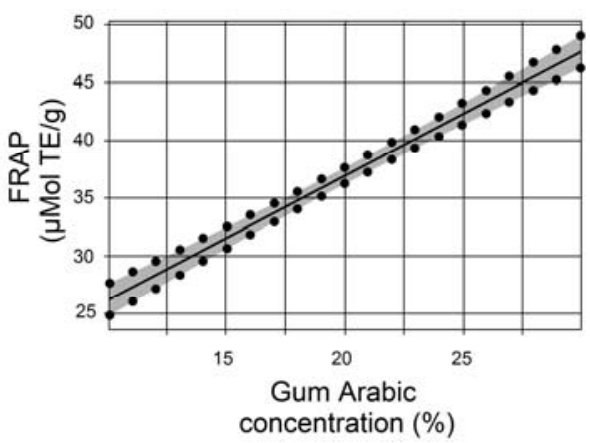

(d)

Fig. 1. Influence of independente variables on the responses: (a) process yield, (b) moisture content and (c) antioxidant capacity by DPPH and (d) FRAP methods

\subsection{Characterization of the powder obtained under the optimum condition}

HIgher process yield and antioxidant capacity were obtained at $160^{\circ} \mathrm{C}$ and $30 \%$ of GA. Under this optimum condition, process yield was $58.7 \%$. The powder presented moisture content of $1.5 \pm 0.2 \%$, antioxidant capacities by FRAP and DPPH methods of $38.9 \pm 1.6 \mu \mathrm{mol}$ $\mathrm{TE} / \mathrm{g}$ and $586.0 \pm 0.1 \mu \mathrm{mol} \mathrm{TE} / \mathrm{g}$, respectively; bulk density of $0.40 \pm 0.01 \mathrm{mg} / \mathrm{ml}$ and mean diameter size of $9.18 \pm 0.33 \mu \mathrm{m}$. Particle size distribution and the morphology evaluated by scanning electron microscopy were shown in Figure 2. Particles presented a continuous wall without fissures or cracks. Such characteristics is desirable to effectively protect the antioxidant compounds. However, particles had an irregular structure, which adversely affect the flow properties of the powders. This morphology can be result from slow film formation during drying of the atomized droplets, causing their shrinkage during the final stages of drying and cooling ${ }^{[14]}$. 


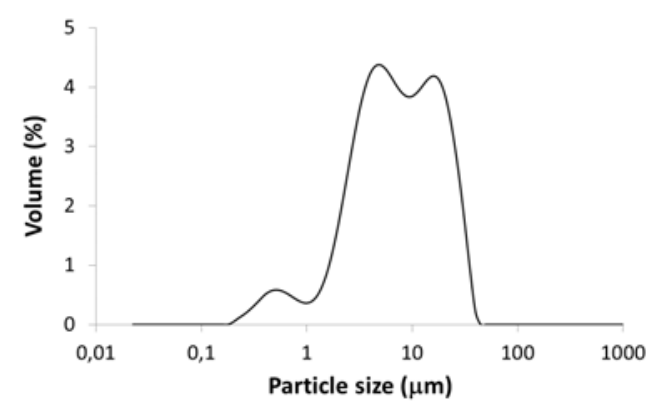

(a)

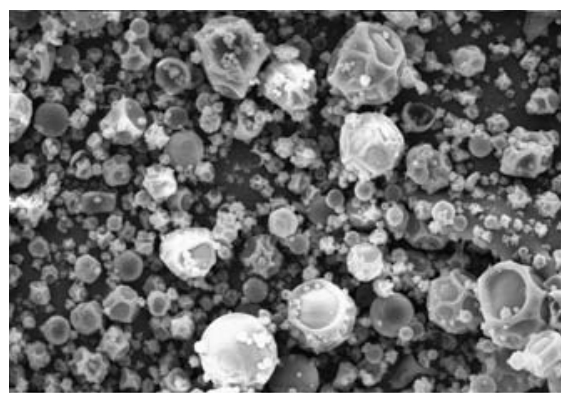

(b)

Fig. 2. Particle size distribution (a) and micrograph of the spray-dried soymilk with magnification of $\times \mathbf{2 0 0 0}$ (b)

\section{Conclusions}

This work demonstrated the significant role of gum Arabic in spray drying of soymilk as an emulsion stabilizer, since there was an improvement on product recovery and retention of antioxidant capacity. In order to obtain maximum process yield and antioxidant capacity, the optimal condition was proposed: $30 \%$ of GA and $160^{\circ} \mathrm{C}$, in which process yield was $58.7 \%$. There was a siginificant retention of antioxidant capacity by donating hydrogen atoms to the DPPH radical (78.9\%) after spray drying; however only $19.4 \%$ of ferric reduction power of soymilk solution was preserved.

\section{Nomenclature}

$\begin{array}{lll}\text { Aw } & \text { water activity } & \\ \text { DPPH } & \text { DPPH scavenging ability } & \mu \mathrm{mol} \mathrm{TE} / \mathrm{g} \text { soymilk solids } \\ \text { FRAP } & \text { ferric reduction power } & \mu \mathrm{mol} \mathrm{TE} / \mathrm{g} \text { soymilk solids } \\ \text { GA } & \text { gum Arabic concentration } & \% \\ \mathrm{~T}_{\text {in }} & \text { Inlet air temperature } & { }^{\circ} \mathrm{C} \\ \mathrm{X} & \text { moisture content } & \% \text { (wet basis) } \\ \mathrm{Y} & \text { process yield } & \%\end{array}$

\section{Acknowledgements}

The authors acknowledge to FAEPEX/Unicamp (14759-17) for the financial support. Olmos, B. would like to thank CNPq for the scholarship. Kurozawa, L. is CNPq Research Fellow. 


\section{References}

[1] Statista. The portal for statistic. Sales volume of soymilk worldwide in 2015 and 2018: 2018. https://www.statista.com/statistics/645662/soy-milk-sales-volume-worldwide (accessed Mar 19, 2018).

[2] Baú, T.R.; Ida, E.I. Soymilk processing with higher isoflavone aglycone content. Food Chemistry 2015, 183, 161-168.

[3] Zhao, D.; Shah, N.P. Changes in antioxidant capacity, isoflavone profile, phenolic and vitamin contents in soymilk during extended fermentation. LWT - Food Science and Technology 2014, 58 (2), 454-462.

[4] Masters, K. Spray drying handbook. Longman Scientific and Technical: London, 1991.

[5] TACO. Brazilian Table of Food Composition / NEPA - UNICAMP. 2004. Campinas: NEPA-Unicamp. 42p. (in portuguese).

[6] Foster, K.D.; Bronlund, J.E.; Paterson, A.H.J. The contribution of milk fat towards the caking of dairy powders. International Dairy Journal 2005, 15(1), 85-91.

[7] Santana, A.A.; Martin, L.G.P.; Oliveira, R.A.; Kurozawa, L.E.; Park, K.J. Spray drying of babassu coconut milk using different carrier agents. Drying Technology 2017, 35(1), 76-87.

[8] Munoz-Ibanez, M.; Azagoh, C.; Dubey, B.N.; Dumoulin, E.; Turchiuli, C. Changes in oil-in-water emulsion size distribution during the atomization step in spray-drying encapsulation. Journal of Food Engineering 2015, 167, 122-132.

[9] Soottitantawat, A.; Yoshii, H.; Furuta, T.; Ohkawara, M.; Linko, P. Microencapsulation by spray drying: Influence of emulsion size on the retention of volatile compounds. Journal of Food Science 2003, 68(7), 2256-2262.

[10] AOAC. Official Methods of Analysis, 19th ed. Association of Official Analytical Chemists International: Washington, D.C, 1995.

[11] Rodrigues MI and Iemma AF. Experimental design and process optimization. CRC Press: Boca Raton, 2014.

[12] Brand-Williams, W.; Cuvelier, M.E.; Berset, C. Use of a free radical method to evaluate antioxidant activity. LWT-Food Science and Technology 1995, 28(1), 25-30.

[13] Benzie, I.F.F.;Strain, J.J. The ferric reducing ability of plasma (FRAP) as a measure of “antioxidant power": The FRAP assay. Analytical Biochemistry 1996, 239(1), 70-76.

[14] Arana-Sánchez, A.; Estarrón-Espinosa, M.; Obledo-Vázquez, E.N.; Padilla-Camberos, E.; Silva-Vázquez, R.; Lugo-Cervantes, E. Antimicrobial and antioxidant activities of Mexican oregano essential oils (Lippia graveolens H.B.K.) with different composition when microencapsulated in $\beta$-cyclodextrin. Letters in Applied Microbiology 2010, $50(6), 585-590$. 